AROUEOLOGÍA Y SOCIEDAD

№ 24, 2012: 249-268

ISSN: $0254-8062$

RECIBIDO: SETIEMBRE DE 2010

ACEPTADO:JUNIO DE 2012

\title{
ENTIERROS DE NIÑOS EN EL SITIO LOTE B Y SU SIGNIFICANCIA SOCIOPOLIITICA PARA EL VALLE BAJO DEL RÍO LURÍN A FINALES DEL PERIODO INTERMEDIO TEMPRANO
}

\author{
SARA MARSTELLER \\ ARIZONA STATE UNIVERSITY \\ smarstel@asu.edu \\ GIANCARLO MARCONE \\ UNIVERSITY OF PITTSBURGH \\ gim2@pitt.edu
}

\section{RESUMEN}

En el presente artículo buscamos integrar el conocimiento que se tiene sobre los patrones funerarios de la cultura Lima con las hipótesis existentes sobre la naturaleza y momento del arribo de esta sociedad al Valle de Lurín. Nuestra objetivo es demostrar como cuando se integra el estudio de los entierros dentro de su contexto temporal y regional estos pueden ayudarnos a clarificar la situación sociopolítica de la región a fines del Intermedio temprano comienzos del Horizonte Medio. Nuestro análisis parte desde el estudio de nueve contextos funerarios encontrados durante las excavaciones realizadas en el año 2009 en el sitio de Lote B, Valle de Lurín.

Palabras Clave: Cultura Lima, patrones funerarios, Lote B, valle de Lurín.

\section{Abstract}

The present paper seeks to relate current knowledge of Lima funerary practices with hypotheses regarding the nature and moment of the arrival of the Lima culture to the Lurín Valley. Our central goal is to show that, when integrated into a regional and temporal context, the study of mortuary practices can help to clarify further the socio-political situation on the central coast of Peru between the end of the Early Intermediate Period and the start of the Middle Horizon. We present a contextualized analysis of burials recovered during the 2009 season at the site of Lote B in the Lurín Valley.

KeYwords: Lima Culture, funerary practices, Lote B, Lurin Valley. 
Desde el inicio de la década pasada el estudio de la cultura Lima ha experimentado un despertar después de muchos años de letargo. Nuevos estudios, principalmente en los valles de los ríos Chillón y Rímac, enfocados principalmente en la re-definición de estilos cerámicos y en la excavación de sitios monumentales, están revaluando los planteamientos tradicionales sobre la complejidad cultural y desarrollo social de la cultura Lima (Ej. Ccencho [1999] 2001; Falcón 2003, Flores 2005; Goldhausen 2001; Mac Kay y Santa Cruz 2000; Narváez 2006; Mogrovejo y Segura 2000; Segura 2001).

Sin embargo, fuera de estos contextos de elites, poco es lo que se ha investigado sobre esta sociedad. Estas omisiones nos impiden generar reconstrucciones integrales de la sociedad Lima, así como de sus procesos socio-políticos. Por ejemplo, en el valle de Lurín, la casi exclusiva atención puesta al Santuario de Pachacamac ha probado ser insuficiente para contestar preguntas sobre el desarrollo sociopolítico del valle durante el Intermedio Temprano. Así como para entender la naturaleza de las relaciones entre la población rural esparcida a lo largo del valle de Lurín y los sitios monumentales de los valles de Rímac y Chillón.

En el presente trabajo, queremos fijar la atención en esta población discutiendo varios contextos funerarios, pertenecientes a niños e infantes, encontrados durante las recientes excavaciones en el sitio de Lote B. Lote B es un pequeño complejo ocupado por una elite rural o local durante el final del Intermedio Temprano y comienzos del Horizonte Medio en el valle bajo del río Lurín. Usaremos estos entierros como una muestra de los patrones funerarios existentes en el valle de Lurín durante el Intermedio Temprano y en base a esta muestra discutir las hipótesis propuestas sobre el momento y la naturaleza de la llegada de la cultura Lima al valle.

\section{INTRODUCCIÓN}

El análisis arqueológico de contextos funerarios constituye una fuente muy rica de información sobre las sociedades del pasado. Tradicionalmente, los estudios funerarios han sido usados principalmente para discutir la organización social, la estructura de las jerarquías sociales o el grado de complejidad social (Binford 1971; Chapman y Randsborg 1981). Estos estudios parten de la idea que los patrones observables en los entierros reflejan directamente la organización social de las sociedades que los crearon. El análisis de las variaciones observables en los diversos aspectos de los entierros como estilos funerarios, ofrendas, orientación, ubicación son particularmente importante para la reconstrucción de roles y relaciones sociales de cada individuo.

Posteriormente se ha reconocido, que los contextos funerarios son más resultado de las acciones de los familiares (los muertos no se entierran por si mismos) que reflejo de quién fue el individuo en vida. Es así, que ahora es claro que las creencias de índole religiosa y filosófica de los deudos probablemente influenciaron también la formación de estos contextos funerarios (Carr 1995; Hodder 1982b). Por ejemplo, estudios en diferentes partes del mundo han demostrado que la variación en algunos aspectos de las prácticas funerarias, como son la preparación y tratamientos del cadáver, frecuentemente están más cerca de factores de carácter religiosos que de factores netamente sociales (Carr 1995). El significado de los objetos colocados al interior de un contexto funerario puede ser muy distinto del que tuvieron estos mismos objetos durante su uso (Hodder 1987). Por lo tanto, estos objetos y/o símbolos reflejan las creencias filosóficas-religiosas, en vez de (o además de), reflejar relaciones sociales (Hodder 1987).

La investigación arqueológica de contextos funerarios ha demostrado que estos también pueden develar detalles del mantenimiento o cambio de las estructuras sociopolíticas de una sociedad. Por ejemplo, los rituales funerarios pueden ser usados para crear y/o reafirmar relaciones comunitarias, identidades y memoria colectiva (Charles y Buikstra 2002; Chesson 2001; Herrera 2007). Ceremonias conmemorativas de un individuo (dependiendo de su rol social) pueden servir para estimular la reflexión sobre el pasado y futuro de la comunidad, y a la vez fortalecer la identificación del grupo 
(Chesson 2001). La investigación arqueológica también ha demostrado que los entierros han sido usados en el pasado para legitimar relaciones sociopolíticas de poder (Hodder 1982; Shanks y Tilley 1982). Por ejemplo, prácticas funerarias, como el re-ordenamiento de huesos desarticulados de múltiples individuos en un solo contexto, pueden enfatizar lo colectivo para enmascarar la realidad de una estructura social en donde el acceso al poder social es disímil (Shanks y Tilley 1982). Inclusive la elección del lugar de enterramiento también puedo ser usado como hito para validar pretensiones sobre determinados recursos o tierras (Goldstein 1981; Saxe 1970). Sin embargo, la elección del lugar de enterramiento y la formación de cementerios son también construcciones sociales del espacio. Creencias filosóficas-religiosas que requieren de separación de muertos y vivos o prácticas funerarias que sirven para re-afirmar la identidad comunal (Charles y Buikstra 2002) también influenciaron la elección del lugar de enterramiento, no tan solo las pretensiones territoriales. Las funciones específicas de las prácticas funerarias son circunstancialmente dependientes y no son exclusivas. Por lo que es de suma importancia considerar el contexto regional y temporal en el análisis de los contextos funerarios (Buikstra 1995).

Los niños en arqueología. Hasta recientemente, los niños han sido largamente excluidos de las reconstrucciones arqueológicas del pasado (Baxter 2008; Kamp 2001; Lillehammer 1989; Sofaer Derevenski 1994). Esta omisión se debe, en parte, a que los niños en nuestra sociedad occidentales no detentan posiciones sociales o económicas privilegiadas, por lo que nuestros marcos conceptuales tienden a pasar por alto el rol que estos jugaron en la construcción y mantenimiento de la sociedad. Sin embargo, estudios etnográficos demuestran que en varias sociedades no occidentales los niños son importantes agentes económicos y sociales, entonces es posible suponer que algo similar ocurriera en el pasado (Bird y Bird 2000; Keith 2005; Sofaer Derevenski 1994). De ahí se desprende la necesidad, al momento de interpretar procesos sociales y políticos del pasado, de no subvaluar los posibles roles que cumplieron los niños. A pesar de este reconocimiento, la mayoría de interpretaciones arqueológicas existentes solo incluyen tangencialmente a los niños, solo en función a sus relaciones con las mujeres y en las esferas domesticas y privadas (Baker 1997). Estos estereotipos son en parte resultado de la dificultad de la arqueología para identificar arqueológicamente espacios y objetos usados exclusivamente por niños, salvo en las raras situaciones donde se ha podido identificar objetos como juguetes en base a la analogía etnográfica (Baxter 2008; Park 2005). Es en los contextos funerarios donde los niños pueden ser identificados con relativa facilidad. Sin embargo, identificar estos contextos funerarios de niños e infantes puede ser extremadamente difícil (Chamberlain 2000; Perry 2006). En parte debido a la pobre preservación de los esqueletos juveniles que son generalmente más delgados y frágiles (Gordon y Buikstra 1981; Walker et al. 1988), o a fallas en los métodos de excavación y recolección (Chamberlain 2000). Asimismo, la existencia de prácticas culturales específicas donde los niños son enterrados en lugares separados de los adultos también ha contribuido a la pobre representación de los niños en el registro arqueológico (Finlay 2000; Stoodley 2000). Los entierros de niños encontrados en Lote B en el año 2009, representan una oportunidad de observar el tratamiento funerario que se les dio a los niños e infantes en el valle de Lurín durante el periodo Intermedio Temprano y el inicio del Horizonte Medio.

En los Andes, tradicionalmente, la investigación arqueológica se ha centrado casi exclusivamente en discutir los contextos funerarios de niños que cumplieron funciones "especiales" como sacrificios rituales (Bourget 2001; Reinhard 1992; Schobinger 1991; Tung y Knudson 2010), mientras que los contextos funerarios de niños con tratamientos seculares (no usados como sacrificios rituales) han sido generalmente ignorados. Es por lo que creemos que el análisis y discusión de los niños encontrados en Lote B constituye un aporte a la discusión general sobre el rol e importancia de los infantes en el desarrollo y mantenimiento de las sociedades andinas del pasado.

En este trabajo discutiremos los contextos funerarios de niños encontrados en Lote B, contextualizándolos en el desarrollo del sitio, así como en comparación con los patrones y practicas fune- 
rarias conocidas para la costa central antes, durante y después del surgimiento de la cultura Lima. Empezaremos por presentar las hipótesis existentes sobre el desarrollo de la estructura sociopolítica Lima y su relación con el valle de Lurín. Luego describiremos las características de los patrones funerarios Lima, sus cambios a través del tiempo y sus correlaciones con los cambios sociopolíticos identificados en la región y asignados como la transición entre el Intermedio Temprano y el Horizonte Medio. De ahí presentaremos los contextos funerarios recuperados en el sitio de Lote B, para finalmente situarlos dentro de su contexto regional y temporal. De esto modo discutir como los detalles de esos entierros pueden ayudar a refinar las hipótesis acerca de la naturaleza del desarrollo político en el valle de Lurín durante este periodo.

\section{LOS LIMA, DESARROLLO Y EXPANSIÓN}

Los valles de la costa central peruana (desde el valle de Chancay hasta el valle del río Lurín) fueron ocupados por la cultura Lima durante el periodo Intermedio Temprano y el inicio del Horizonte Medio (aprox. 0-700 d.C.) (Kaulicke 2000). El estudio de la cultura Lima ha estado mayoritariamente centrado en el desarrollo de cronologías estilísticas. Inicialmente los arqueólogos que investigaron el área reconocieron la presencia de dos fases estilísticas dentro del llamado estilo Lima (Kroeber 1926, 954; Strong y Corbett 1943; Stumer 1953; Willey 1943). Estas dos fases fueron identificadas con distintos nombres como Playa Grande, Interlocking, Proto-Lima, Maranga. El uso indiscriminado y confuso de los nombres por los distintos autores y la falta de claridad en los criterios estilísticos usados para sostener esta separación cronológica generaron una confusión entre estos términos estilísticos (Flores 1981; Montoya 1995; Patterson 1966). A pesar de esta confusión aparente, en 1953 en el marco de la "Mesa redonda sobre terminología en la arqueología peruana" (Varios 1953) los diversos investigadores participantes acordaron el uso de los términos Playa Grande y Maranga como los nombres validos para las fases temprana y tardía del estilo cerámico Lima de la costa central peruana durante el Intermedio Temprano. Estos cambios identificados en la cerámica, correlacionan con cambios en la organización sociopolítica de la región, identificados en el aumento de la cantidad y monumentalidad de edificios públicos, cambios en los patrones funerarios y una supuesta intensificación agrícola (Kaulicke 2000).

A pesar del aparente consenso logrado en 1953, Thomas Patterson sintió que era necesario realizar, para su disertación doctoral, una redefinición de las separaciones estilísticas y tipológicas del estilo Lima. Él pensaba que éstas "reflejaban diferencias cronologías solo en una manera muy general" (Patterson 1966: 1. La traducción es nuestra). Para Patterson (1966) esta separación en dos fases tenía alguna significancia temporal pero sus divisiones eran demasiado gruesas como para constituir un marco cronológico apropiado para el estudio de la sociedad Lima. Él se propuso realizar una seriación de la cerámica Lima con el fin de desarrollar una cronología relativa muy fina y detallada para este periodo en la costa central, para luego relacionarla con la secuencia cronológica maestra propuesta por John Rowe para toda el área andina (Patterson 1966:3).

Patterson desarrolló esta seriación de la cerámica Lima recolectando fragmentos pertenecientes a diferentes sitios de los valles del Chillón, Rímac y Lurín. Algunos de estos materiales tenían asociación estratigráfica, lo que fue usado por él para darle una dirección temporal a su secuencia cronológica final compuesta por nueve fases. Estas asociaciones estratigráficas también fueron usadas por Patterson para sustentar la idea de cada una de estas fases correspondían a unidades cronológica independientes que fueron sucesivas entre sí (Patterson 1966:1).

Patterson relacionó sus nueve fases Lima con la secuencia maestra de Rowe en el valle de Ica y localiza el inicio de la secuencia Lima en el periodo Intermedio Temprano y la ultima fase de este estilo (fase 9) en la fase 1A del Horizonte Medio (Patterson 1966). Para el inicio de la época 1B del Horizonte Medio este estilo fue abandonado y/o transformado en un nuevo estilo (Nievería) que fue el resultado de la mezcla de las tradiciones locales Lima y rasgos Wari. Este estilo fue tomado como símbolo 
inequívoco de la presencia y hegemonía de Wari en el área (ver discusión de estas ideas en Kaulicke 2000; Menzel 1964; Patterson 1966; Segura 2004).

En los últimos años, excavaciones en varios sitios asociados a la cultura Lima vienen probando que, aunque las fases de Patterson son útiles como criterio general de organización, su valor temporal es dudoso ya que representa una sobre división en unidades temporales que no tienen sustento en la estratigrafía o en la historia de ocupación de cada sitio. Por ejemplo, varios investigadores han encontrado la coexistencia de las ultimas tres fases de la secuencia Lima de Patterson en los mismos contextos estratigráficos que fragmentos en estilo Nievería, sugiriendo que estas tres ultimas fases (7,8 y 9) y Nievería son al menos parcialmente contemporáneos (Ccencho 2001; Guerrero y Palacios 1994; Kaulicke 2000; MacKay y Santa Cruz 2000; Mogrovejo y Segura 2000; Narváez 2006; Segura 2001, 2004; Shady y Narváez 2000).

Como Segura (2004) acertadamente señala, el trabajo de Patterson adolece de un problema de representatividad. Tanto la cantidad de fragmentos (tamaño de la muestra) como el sesgo al recolectar la muestra hacen que las inferencias de Patterson sean solo útiles como hipótesis iniciales a ser examinadas. Segura específicamente muestra (Segura 2004: Cuadro 1) como si analizamos la distribución de las fases de Patterson de acuerdo a los sitios de procedencia, vemos que las diferencias entre la cerámica podrían corresponder a variaciones regionales más que temporales (ver también Lavalle 1966 para un planteamiento similar).

A pesar que no es nuevo cuestionar el valor cronológico de estas fases, los investigadores seguimos usando estas fases como un marco referencial general para hablar de la cultura Lima. Los criterios usados por Patterson para definir sus fases, aun son usados para discutir la cronología. En general, asumimos que las fases 7, 8 y 9 corresponden a Lima Tardío (Segura 2001, 2004) mientras que las fases 4 a 6 corresponderían más o menos a Lima Medio (Escobedo y Goldhausen 1999: 10).

Es en parte debido a que el estudio de la cultura Lima ha estado demasiado enfocado en esta discusión estilística, que hemos dejado de examinar la cronología a partir de la evidencia estratigráfica y de ocupación en los sitios. Lo cual nos ha impedido relacionar estos periodos cronológicos con cambios en el desarrollo cultural de esta sociedad. Por ejemplo, ¿Qué procesos sociopolíticos se encuentran detrás de las transformaciones estilísticas, arquitectónicas y de asentamiento, que parecen caracterizar el paso de Lima Medio a Lima Tardío? ¿Cuál fue la naturaleza de este cambio?

La evidencia apunta a un incremento en la centralización política durante el periodo conocido como Lima Tardío. Para algunos investigadores, basadas principalmente en contextos funerarios de elite, estilos cerámicos y arquitectura monumental, este incremento en complejidad política es resultado de procesos de intercambio interregionales, ya sea por su participación en redes suprarregionales de intercambio de objetos de prestigio (Shady 1982,1988) o debido a relaciones clientelares, o de emulación, con el supuesto Imperio Wari (Isla y Guerrero 1987; Kaulicke 2000; Menzel 1964). En contraste, las interpretaciones construidas en base a los patrones de asentamiento y artefactos de superficie, proponen un desarrollo basado en una economía política autóctona desarrollada en base a: la dominación de la elite sobre recursos económicos y control del excedente, intensificación agrícola, flujo interno de bienes y/o la movilización de fuerza laboral a través de sistemas de parentesco (Dillehay 1979; Earle 1972; Kroeber 1926; Patterson et al. 1982; Stumer 1954b).

A nivel subregional, el momento y la naturaleza de la expansión de la cultura Lima desde el norte (el valle del Rímac) al valle del Lurín esta todavía pobremente entendido. Una hipótesis, sostiene que los cambios en el patrón de asentamiento y de la distribución cerámica en el valle de Lurín a fines del Intermedio Temprano, reflejan una expansión de una organización política fuerte, de nivel estatal (lo que correspondería al periodo Lima Tardío), en el área (Earle 1972; Patterson, et al. 1982). Bajo esta hipótesis la presencia o intromisión Lima en el valle bajo del Lurín sería un proceso relativamente tardío en la secuencia Lima, que trajo consigo un nivel de centralización sociopolítica antes desconocida por la población del valle (Earle 1972; Patterson et al. 1982). Una hipótesis alternativa 
propone que el valle de Lurín estaba organizado en cacicazgos, basados en relaciones de parentesco, que fueron incorporados a la cultura Lima entre las fases Lima Temprano y Medio (Makowski 2002). Makowski (2002: 117) complementa su explicación mencionado que los cambios identificados a final del Intermedio Temprano en el valle de Lurín, no son resultado de una expansión Lima Tardío, sino consecuencia de la influencia y expansión Wari en la costa central. Sin embargo, antes del trabajo presentado en este articulo no se han realizado excavaciones sistemáticas de un sitio asociados a materiales Lima en el valle de Lurín fuera de los edificios de Pachacamac. Por lo que ambas hipótesis son hasta el momento imposibles de confirmar. Nosotros pensamos que los datos de Lote B pueden representar una contribución clave en la evaluación de las hipótesis arriba expuestas.

\section{EL PATRÓN FUNERARIO LIMA}

En los entierros en "estilo Lima" Clásico, el cuerpo fue colocado en posición extendida sobre una litera construida con cañas y amarradas con cuerdas de fibra vegetal (Flores 2005; Kaulicke 2000; Kroeber 1926). Las ofrendas usualmente incluyen vasijas cerámicas con decoraciones en estilo Lima, mates, husos y adornos personales como tupus y collares. Existen algunas variaciones dentro de este patrón, estas han sido observadas en factores como la posición del cuerpo, la orientación de la cabeza, así como en el número de artefactos asociados. Entierros en este estilo Clásico Lima han sido descubiertos en el valle del Chillón en sitios como Cerro Culebras (Stumer 1954a) y Playa Grande (Stumer 1953), y en el valle del Rímac en Cajamarquilla (Sestieri 1971), Maranga (Jijón y Caamaño 1949) y la Huaca Pucllana (Flores 2005) entre otros.

Durante el inicio del Horizonte Medio, sucede un cambio significativo en el estilo de enterramiento en la costa central. Los entierros extendidos sobre una litera de caña son remplazados con entierros sentados en posición fetal y envueltos en varias capas de textiles de algodón y amarrados con cuerdas de fibra vegetal. Varios entierros en este estilo "fardo flexionado" han sido recuperados de sitios como Ancón en el valle del Chillón (Ravines 1981) y Cajamarquilla en el valle del Rímac (Sestieri 1971). Esta transición ha sido interpretada como evidencia de la influencia serrana de los Wari (Menzel 1964; Makowski 2002) y el estimulo que esta política pan-andina impulso para rechazar algunos aspectos de la ideología Lima (DeLeonardis y Lau 2004; Ravines 1981). Ahora bien este estilo de enterramiento, en fardo y flexionado, se encuentra presente en la costa central con anterioridad a la presencia del desarrollo de la cultura Lima. Desde inicios del Intermedio Temprano encontramos fardos de individuos flexionados, similares a los fechados en el Horizonte Medio, en sitios como Villa El Salvador y Tablada de Lurín en el valle del río Lurín (Cárdenas 1999; Makowski 2002; Pechenkina y Delgado 2005; Stothert y Ravines 1977). Esto sugiere que el uso de este estilo al final del Intermedio Temprano y comienzos del Horizonte Medio pudo haber representado un retorno a tradiciones funerarias anteriores, al ocaso de la tradición Lima (DeLeonardis y Lau 2004).

En ambos casos, los entierros en estilo Lima Clásico y los entierros en estilo fardo flexionado, tanto del Intermedio Temprano como del Horizonte Medio, no presentan variaciones especificas relacionadas a las edades de los individuos, aunque los entierros de niños son generalmente menos elaborados y con menos ofrendas (Ravines 1981; Stothert y Ravines 1977). A pesar de estas ligeras diferencias es posible afirmar que estos estilos no eran dependientes de factores sociales como edad o géneros. En muchos casos, estos entierros de niños comparten el mismo patrón funerario básico que los adultos (Flores 2005; Ravines 1981; Stothert y Ravines 1977; Stumer 1954a).

\section{LOTE B}

Nuestro estudio se enfoca en el sitio de Lote B, también conocido como Cerro Manchay, en el valle bajo de Lurín (UTM 8654850N, 297400E) (Fig. 1). El sitio se encuentra estratégicamente localizado en la cima de una colina con vista tanto a la quebrada de Manchay (posible ruta de comunicación en la 
antigüedad entre los valles de Lurín y Rímac) como al valle de Lurín (Fig. 2). En base a sus características superficiales, se identificaron cuatro sectores en el sitio (Fig. 3). En el año 2009 se realizaron excavaciones prospectivas en cada uno de los cuatro sectores y revelaron al Lote B como un pequeño complejo residencial de elite, ocupado durante buena parte del periodo Intermedio Temprano y el comienzo del Horizonte Medio (lo que correspondería a las fases media y tardía de la secuencia Lima).

El sector 1 presentó evidencia de actividades de festines y banquetes, asociados a estructuras de almacenamiento. El sector 2, adyacente al sector 1, presentó estructuras que han sido interpretadas de uso residencial. Los materiales asociados recuperados a este sector son de uso doméstico, con la excepción de la cerámica, que es muy fina y altamente decorada en estilo Lima. Estos dos sectores probablemente funcionaron juntos formando un pequeño complejo residencial, esto es por las evidencias de haber sido ocupado durante un largo tiempo. La cerámica recuperada en estos dos sectores esta compuesta por fragmentos de estilo Lima Medio, en sus fases tempranas de ocupación. Esta asociación sugiere una influencia de la cultura Lima en el valle de Lurín desde tiempos Lima Medio. En la última fase de ocupación se produce un aumento de la cerámica decorada, estilísticamente más semejante a la cerámica Lima Tardío (Fig. 4). En esta última fase el sector 1 presenta un claro incremento en las actividades de festines y banquetes rituales, así como nuevas estructuras de almacenamiento. Contemporáneo con este momento de incremento de actividades en el sector 1 , se construyen en el sitio dos nuevos edificios en el sector 3 y en el sector 4 respectivamente.

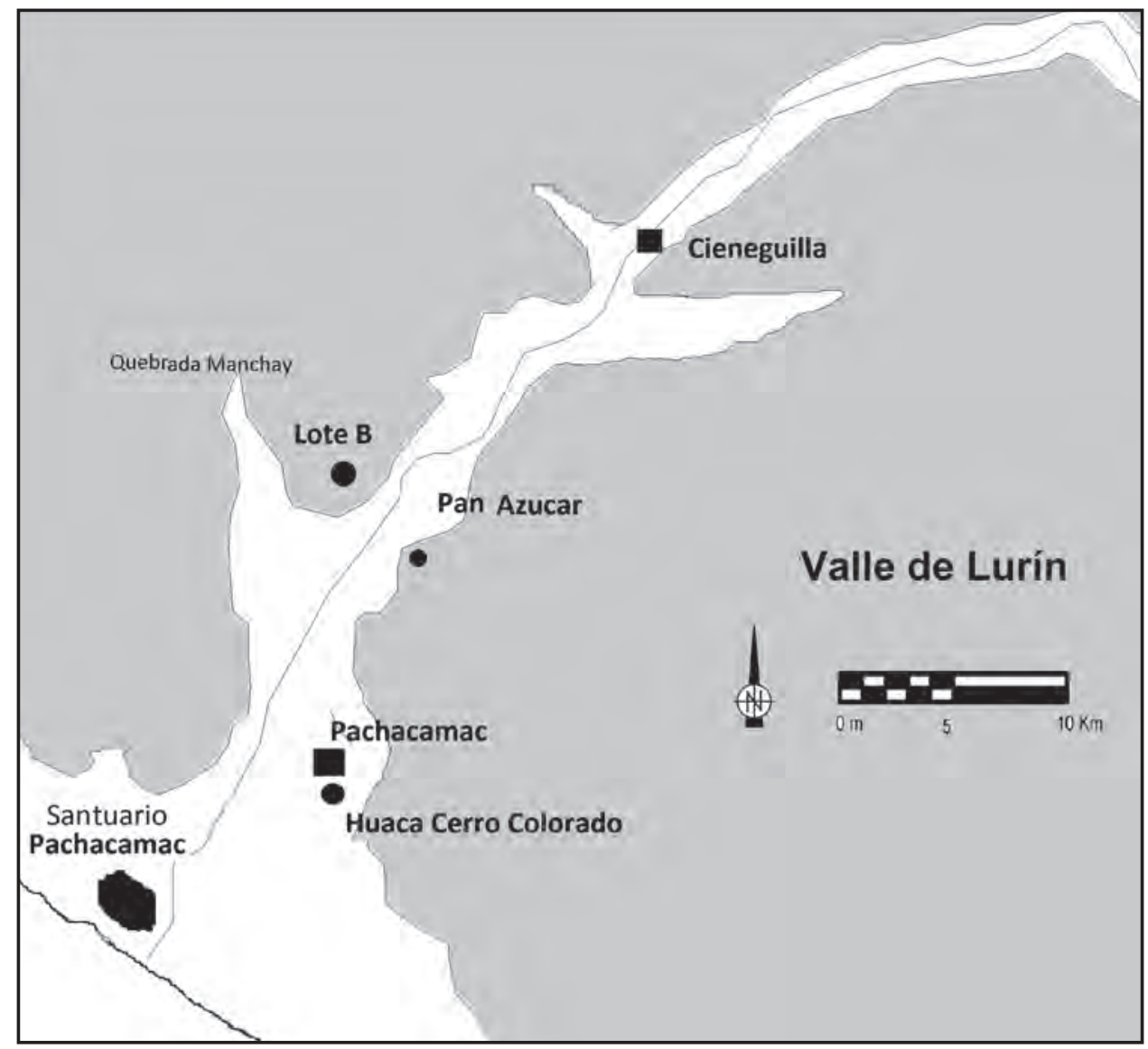

Figura 1: Valle de Lurín con sitios pertenecientes al periodo Intermedio Temprano basado en Patterson et al. (1982). 


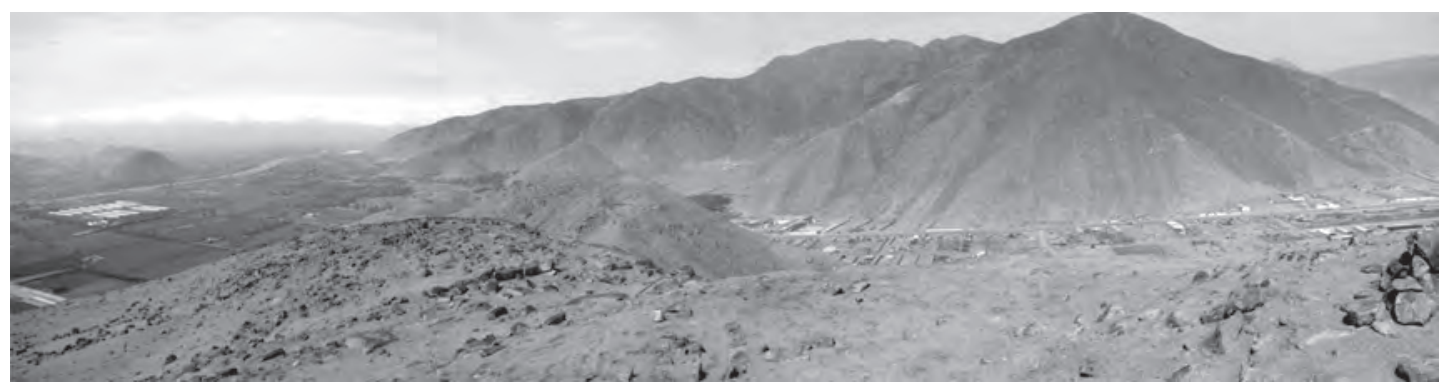

Figura 2: Vista desde Lote de la intersección del Valle de Lurín y la quebrada de Manchay.

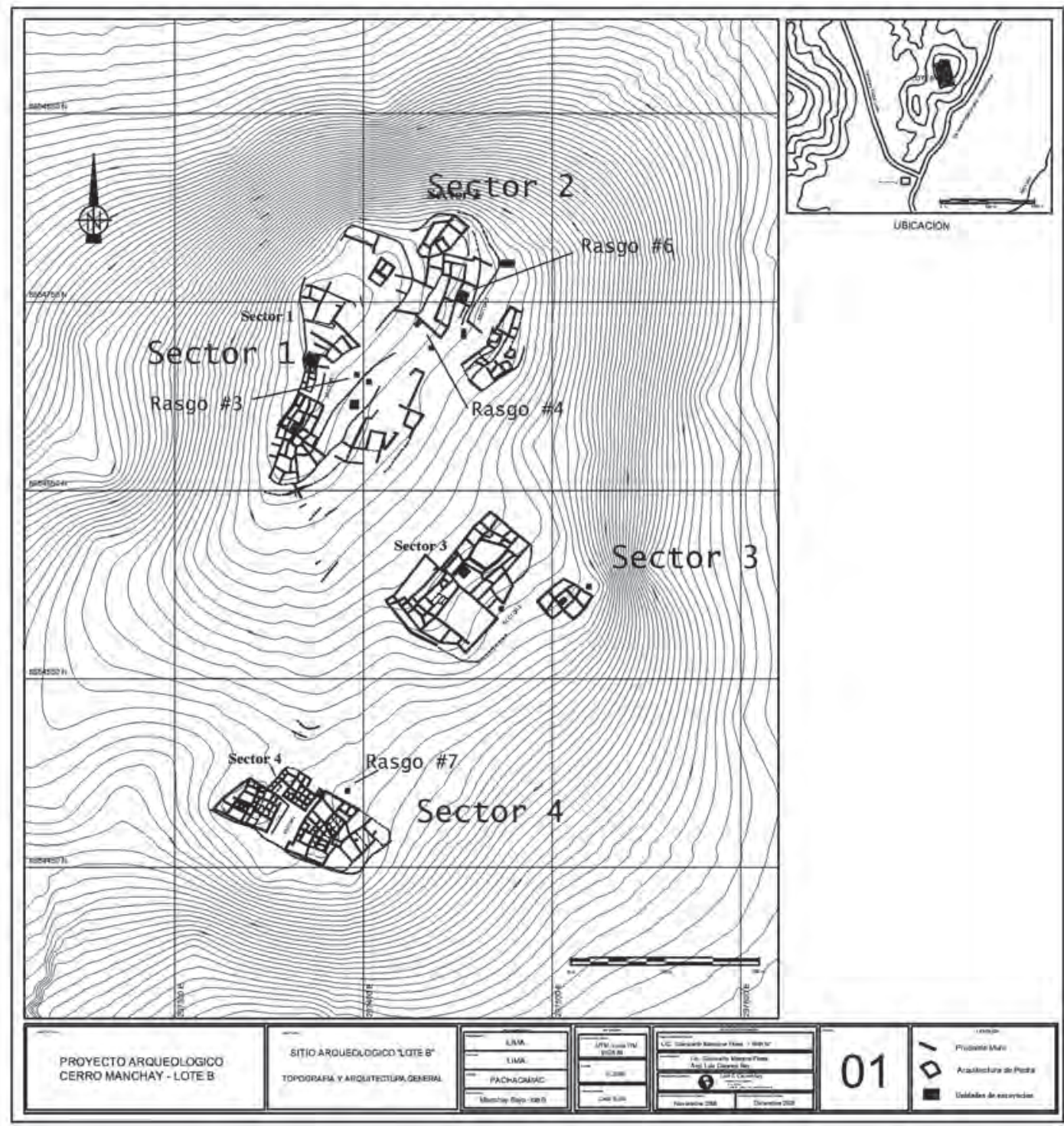

Figura 3: Mapa de Lote B, con la ubicación de los rasgos mencionados en el texto. 

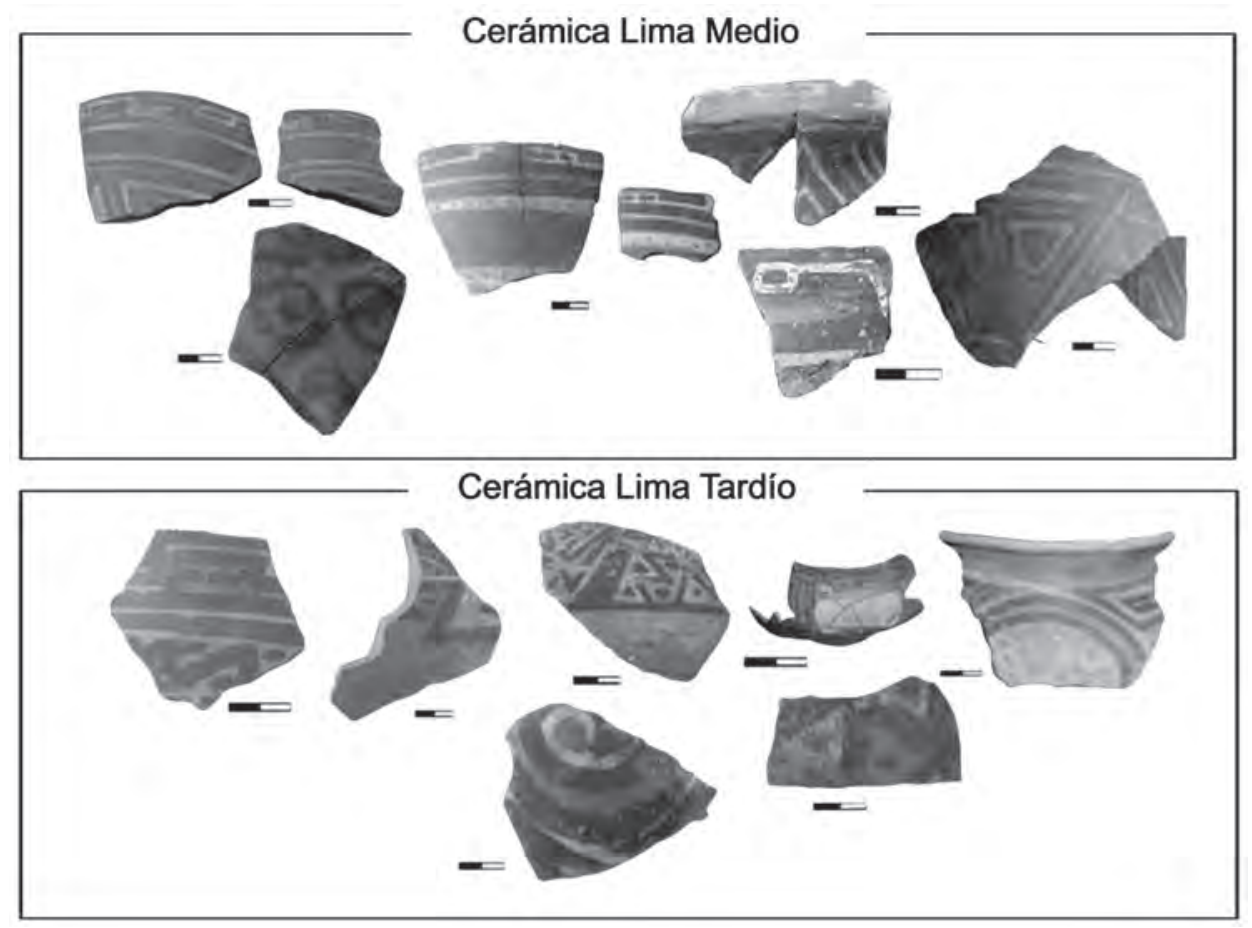

Figura 4: Cerámica recuperada en Lote $B$.

Este edificio, presente en el sector 3, tiene una forma rectangular, está pintado de amarillo y asociado enteramente a cerámica Lima Tardío. Otra construcción de carácter intrusivo asociada a material exclusivamente tardío, fue encontrada en el sector 4. Esta edificación de planta rectangular estuvo aparentemente dedicada a actividades de almacenamiento. La construcción de estos edificios, como ya dijimos, es contemporánea con el incremento de la presencia de cerámica Lima Tardío, mayor evidencias de festines rituales, la construcción de estructuras de almacenamiento y una mejora en los materiales constructivos del área residencial identificada en el sector 2.

\section{ENTIERRos DE NIÑOS EN LOTE B}

Durante las excavaciones del año 2009 en Lote B, siete entierros que contenían nueve infantes y niños fueron descubiertos en tres de los cuatro sectores del sitio. Estos entierros se presentaron en dos estilos muy distintos. En el primer estilo, el cuerpo se encuentra extendido envuelto en una litera de cañas o esteras. La litera era mantenida en su lugar con delgadas cuerdas de fibra vegetal. Como mencionamos más arriba este patrón corresponde al patrón funerario Clásico Lima que ha sido registrado en varios sitios de la región (Jijón y Caamaño 1949: 95; Sestieri 1971: 102; Stumer 1953, 1954a: 221).

El segundo estilo de entierro presente en Lote B es en fardos textiles donde el individuo estaba en posición flexionada. Como mencionábamos líneas arriba, este parece haber sido un estilo tradicional en el valle de Lurín, identificado al menos desde el Formativo Tardío (Makowski 2002; Pechenkina y Delgado 2005; Stothert y Ravines 1977), que se supone reaparece de nuevo a comienzos del Horizonte Medio (DeLeonardis y Lau 2004; Menzel 1964; Ravines 1981).

En Lote B encontramos entierros extendidos en estilo Lima pertenecientes a la ocupación más temprana del sitio, que proponemos estuvo asociada a cerámica Lima Medio. En el sector 2, el entierro identificado como rasgo \#6 (Fig. 5) contenía a un niño de un año de edad colocado de manera super- 


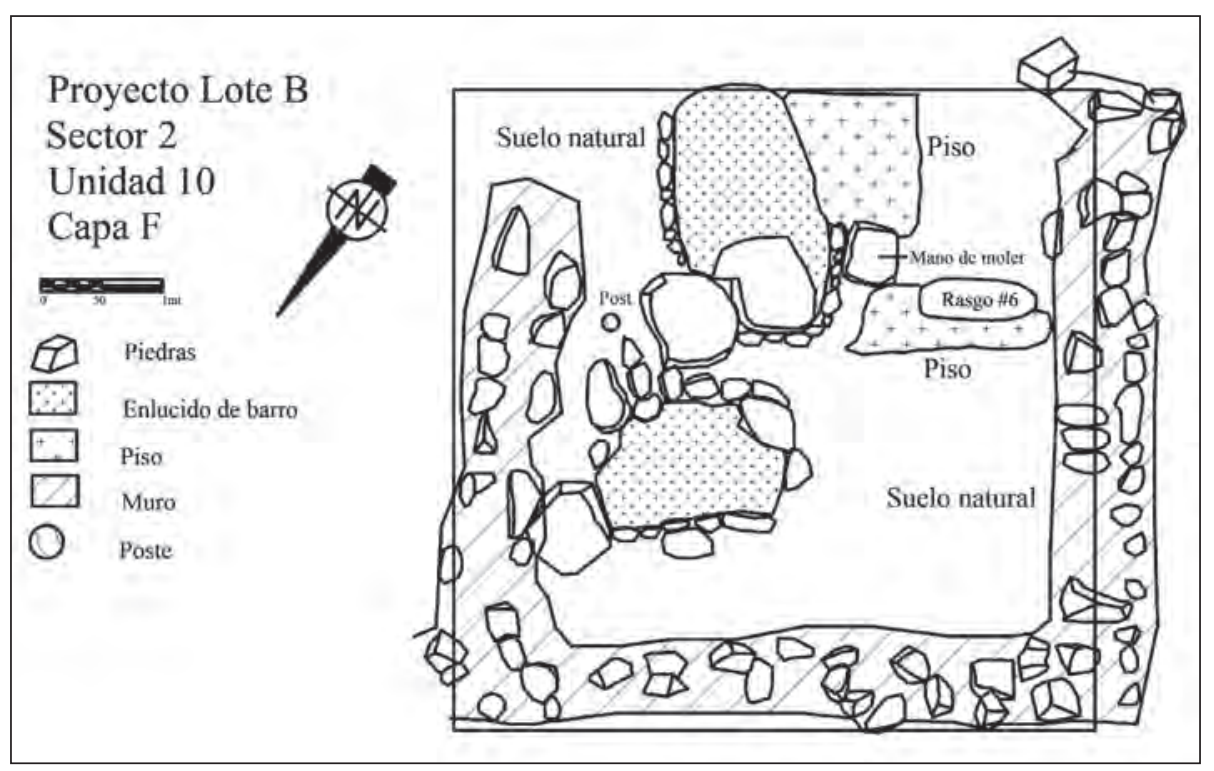

Figura 5: Ubicación del rasgo \#6 en la Unidad 10, Capa F.

ficial directamente sobre el piso de la ocupación más temprana de un recinto, a unos pocos metros de lo que pensamos fue el acceso del recinto. El individuo se encontraba cubierto en un envoltorio de esteras y cañas, colocado sobre el piso en posición extendida con la cabeza orientada hacia el sur. Stumer (1954a) reporta entierros de niños similares en el sitio de Cerro Culebras en el valle del Chillón. Stumer encontró en tres diferentes contextos a: "un infante o niño muy pequeño completo, con una litera en miniatura, no en tumba, sino meramente puesto sobre el piso de la entrada" (Stumer 1954a: 221. La traducción es nuestra).

Otros entierros en estilo Lima Clásico, fueron descubiertos en el sector 4 de Lote B. Estos entierros eran parte de la acumulación de entierros identificada como rasgo \#7 (Fig. 6). Este rasgo esta ubicado debajo de un basural con fragmentos cerámicos Lima Tardío y asociado a la estructura de almacenamiento adyacente descrita más arriba. En este rasgo se recuperó un total de cinco individuos correspondientes a cuatro entierros excavados en una unidad de 2 × $2 \mathrm{~m}$. En base a esta acumulación en tan reducido espacio, pensamos que el área pudo haber sido usada como cementerio. De ser así, este cementerio fue cubierto y abandonado antes de la construcción de la estructura de almacenamiento.

Los dos entierros en estilo funerario Lima de este rasgo, individuo \#2 e individuo \#5, estuvieron colocados en posición extendida y envueltos en tapetes de cañas, amarradas con cuerdas de fibra vegetal. Entre el individuo y el envoltorio de caña estos entierros presentaron evidencia de un textil muy delgado y estaban asociados a un pequeño mate. La posición del individuo \#2 es algo inusual (Fig. 7), pensamos que este individuo se encontró inicialmente en posición extendida y luego forzado a caber en una fosa/matriz estrecha. Esta fosa fue posteriormente tapada con una roca de gran tamaño. El individuo \#5 se ubicaba en una fosa al centro de la unidad de 2 × $2 \mathrm{~m}$. Este individuo tenía unos 9 meses de edad al momento de su muerte, que fue colocado en posición extendida sobre una estera y acompañado, como ofrenda, de un ave (Fig. 8). Este individuo, compartía la misma fosa con el individuo \#4, un infante de 6 meses de edad envuelto en un fardo textil en posición flexionada mirando al este. El individuo \#5 también presentó algo de disturbio y señales de movimiento que pensamos son resultado del posterior enterramiento del individuo \#4. En Cajamarquilla, Sestieri (1971:103) encontró una intrusión similar de un entierro en fardo intrusivo a un entierro en litera. 


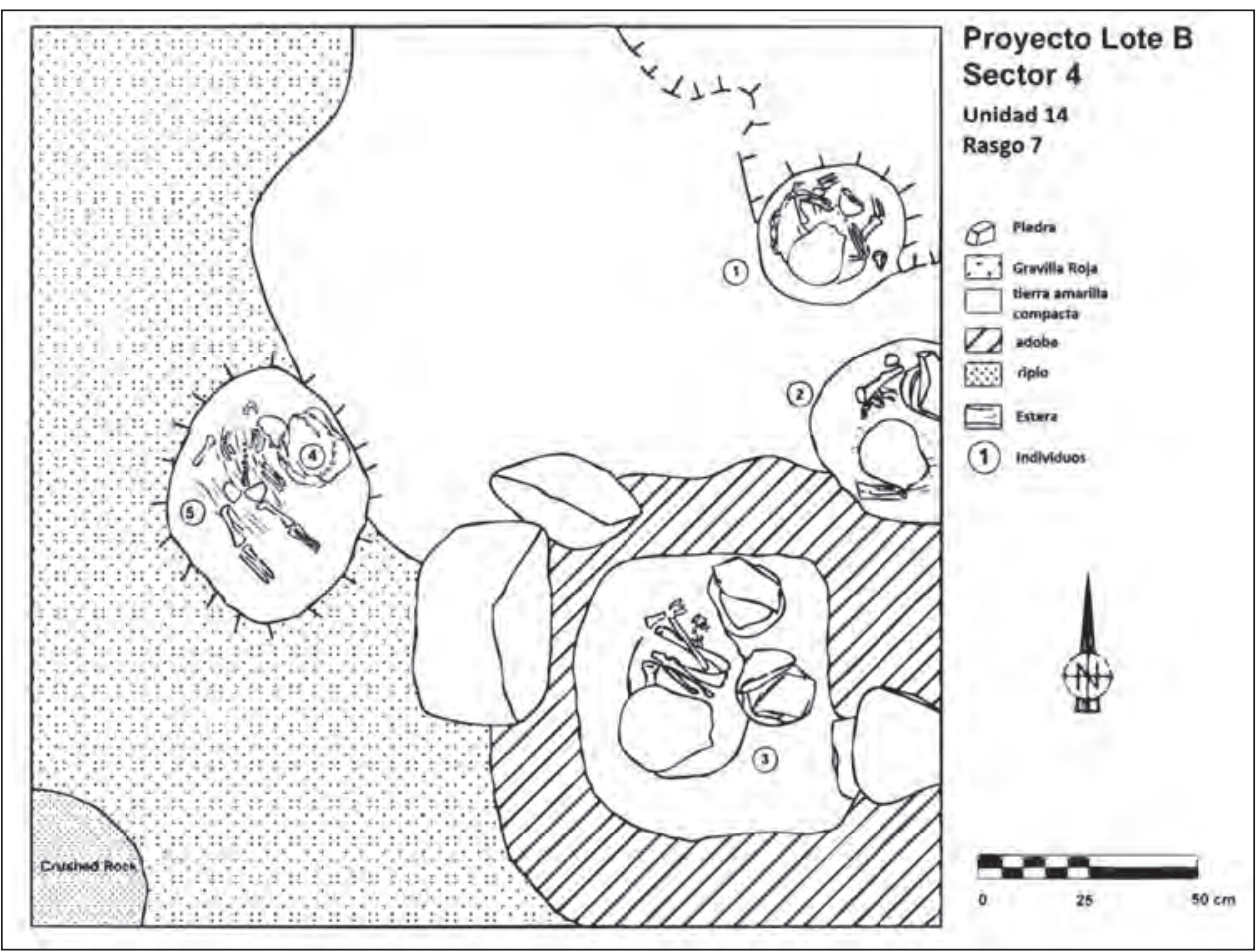

Figura 6: Rasgo \#7 de la unidad 14.

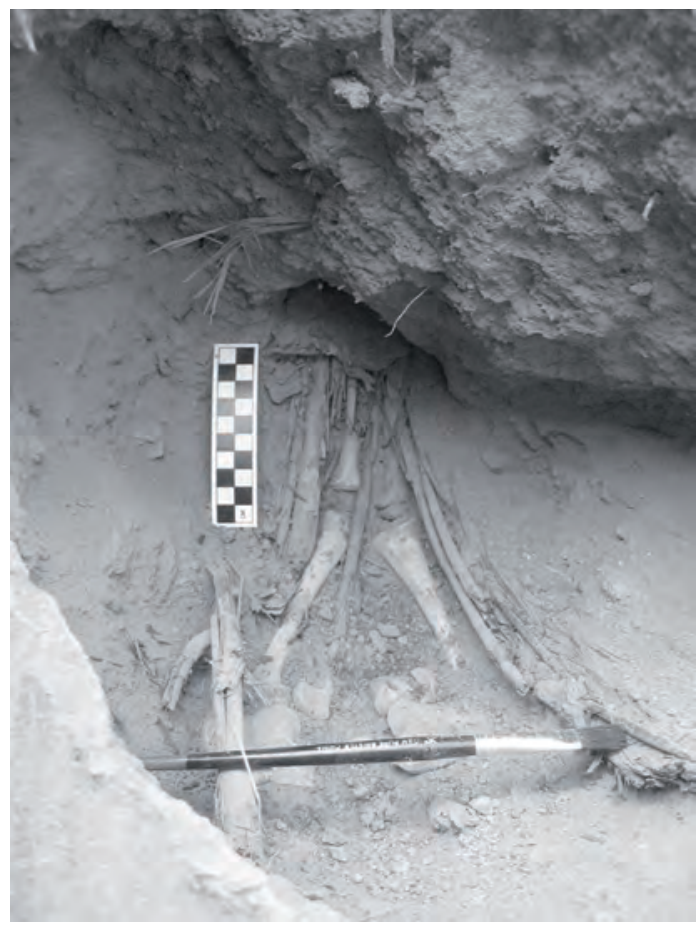

Figura 7: Detalle del Individuo \#2 del Rasgo \#7

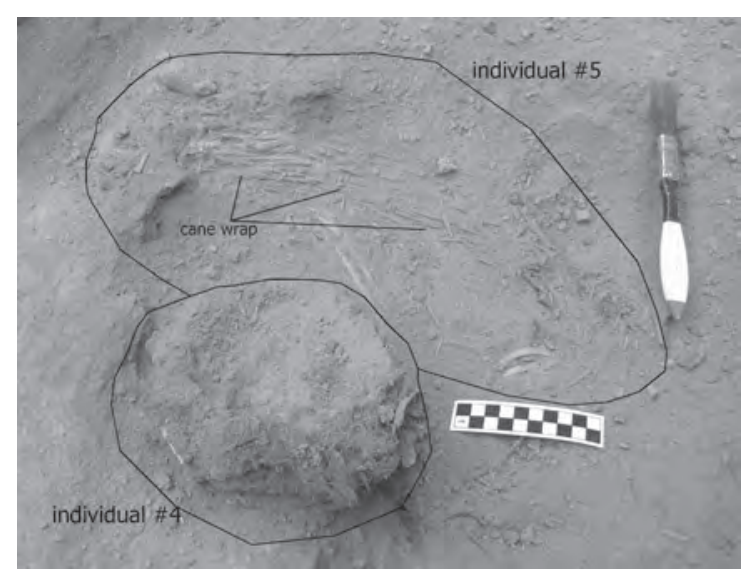

Figura 8: Detalle del Individuos \#4 y \#5 del Rasgo \#7 
El rasgo 7, presentó también individuos en posición sentada envueltos en fardo textil. Aparte del ya mencionado individuo\#4, el individuo \#1, de 9 meses de edad, se encontraba mirando el noreste y tenía como ofrenda dos pequeños mates. El Individuo \#3, de unos 2 años al momento de su muerte, también colocado en posición flexionada y envuelto en un fardo textil, fue el único presente en una tumba que incluía una pequeña estructura construida al interior de la fosa (Fig. 9). Esta estructura tenía planta semicircular y estaba construida con tierra compactada y piedras. Asociados a este individuo encontramos dos mates cubiertos con piedras planas colocadas como si fueran tapas, puestos al frente del individuo a la altura del cráneo. La fosa de este entierro fue sellada con una compactación dura de tierra y cubierta con dos rocas de gran tamaño. Es claro que las bocas de los entierros del rasgo \#7 fueron hechas antes y cubiertas luego por el basural y el edificio de almacenamiento del sector 4 asociados íntegramente a cerámica Lima Tardío (Fig. 10).

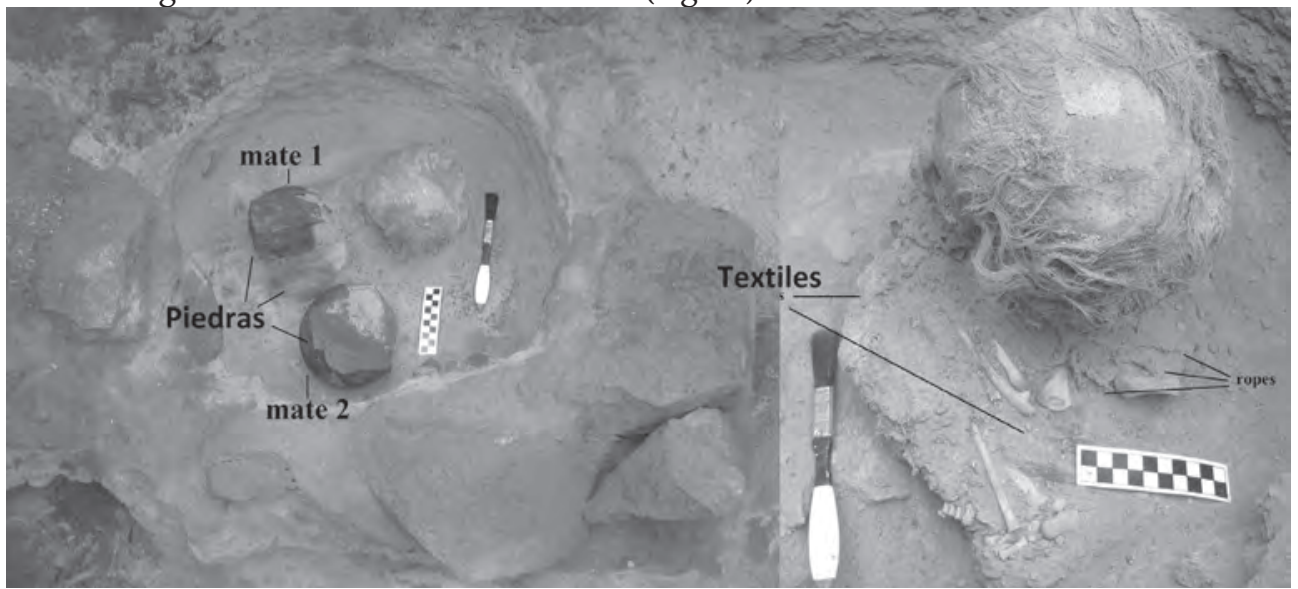

Figura 9: Detalle del Individuo \#3 del Rasgo \#7.

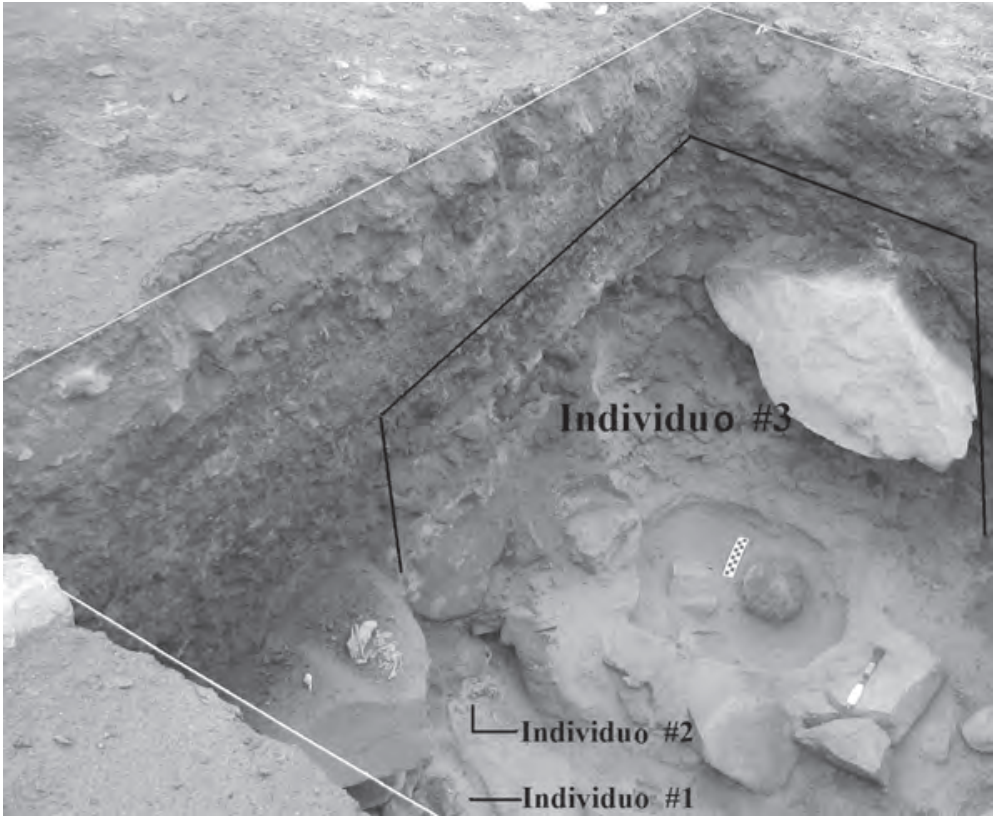

Figura 10: Detalle del perfil de la Unidad 14, mostrando superposición del basural sobre los contextos funerarios del Rasgo \#7. 
Otros dos entierros fueron descubiertos en Lote B. Estos fueron descubiertos en los basurales de los sectores 1 y 2. Las bocas de las fosas de estos dos entierros corresponden a los niveles de abandono del sitio, probablemente a comienzos del horizonte medio, e implican que estos fueron depositados en los basurales después de que se dejó de utilizar el sitio. El rasgo \#3 (fig. 11) fue hallado en uno de los basurales del sector 1 y estaba compuesto por un fardo donde el individuo estaba en posición flexionada. El individuo contenido en el fardo tenía unos 7 años de edad y estaba orientado al noreste. Este fardo se encontraba asentado sobre una cama de pequeñas piedras y asociado a un mate.

El sector 2 se encontró un entierro doble, donde dos fardos habían sido colocados en una fosa construida sobre una acumulación de basura adyacente al muro perimétrico del complejo residencial del Sector 2. Este entierro fue identificado como rasgo \#4. Una pequeña concentración de piedras marcaba la boca del entierro, el individuo superior (Fig. 12) era un infante de nueve meses de edad enterrado sobre un segundo niño de 3 años de edad al momento de su muerte (Fig. 13). Los dos se encontraban en posición flexionada, envueltos en textiles y mirando al noreste. Dos pequeños mates se encontraron asociados al individuo inferior.

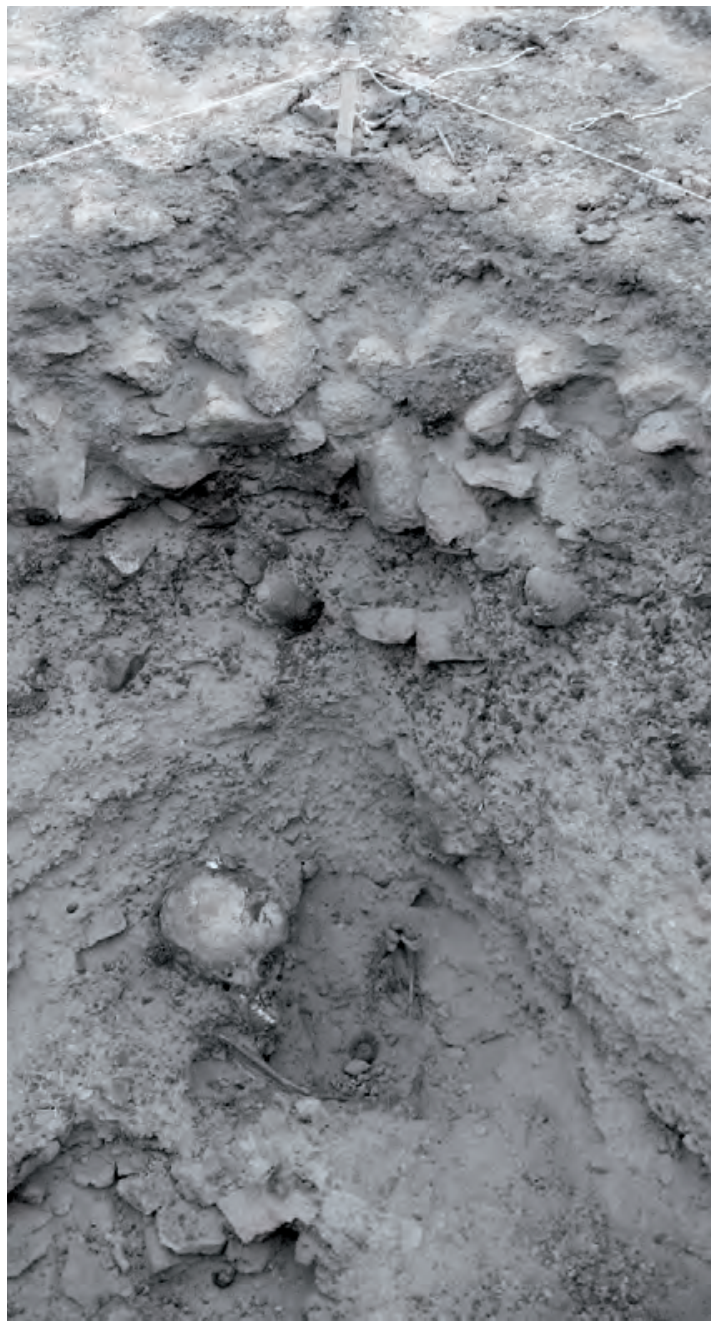

Figura 11: Rasgo \#3 en el perfil de la Unidad 2.

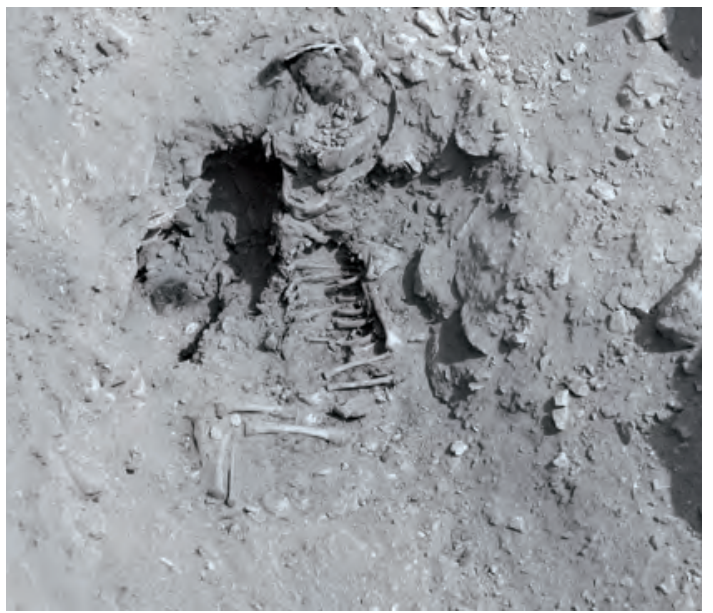

Figura 12: Detalle del Individuo \#1 del Rasgo \#4.

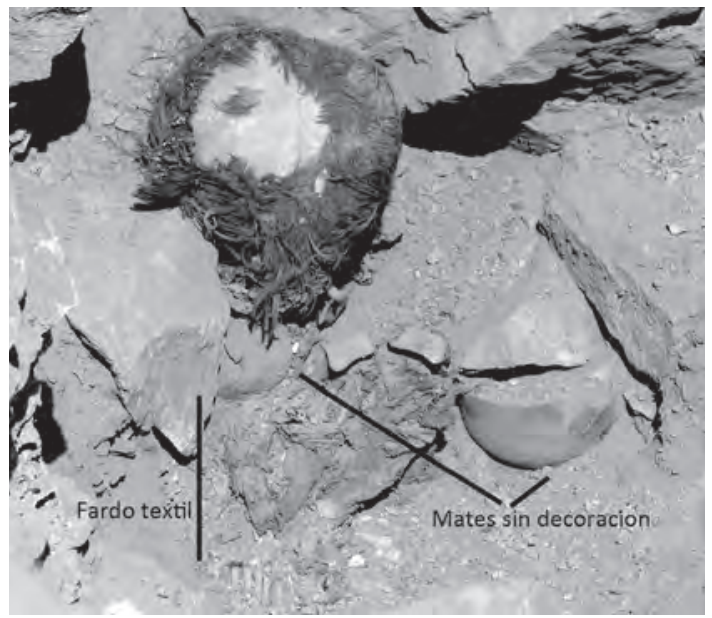

Figura 13: Detalle del Individuo \#2 del rasgo\#4. 


\section{Discusión}

Aunque los entierros recuperados en el Lote B son pocos en número, cuando se sitúan dentro de su contexto regional y local, sus características únicas nos permiten evaluar varias hipótesis acerca del desarrollo sociopolítico del valle de Lurín durante la última parte del Intermedio Temprano y el inicio del Horizonte Medio. Primero, la presencia de entierros en el estilo Lima Clásico durante las fase más temprana de la ocupación en el sitio sugieren que la adopción de la ideología y prácticas culturales Lima empezó durante las fases medias del Intermedio Temprano. La coexistencia de este estilo (en esteras) con prácticas funerarias locales (en fardos) dentro del rasgo \#7, demuestra que las prácticas funerarias Lima no fueron excluyentes.

Una pequeña proporción de entierros en fardo y flexionados, contemporáneos con los entierros extendidos sobre litera de caña, han sido encontrados en sitios como Cajamarquilla, Ancón y Maranga (Mac Key y Santa Cruz 2000; Menzel 1964; Ravines 1977; Sestieri 1971). Esta variación en el patrón funerario implica un cierto grado de resistencia o libertad de elección bajo la influencia de la cultura Lima. Es así, que una influencia foránea (como Wari) no sería necesaria para promover el retorno de practicas funerarias tradicionales, después de terminar la influencia Lima. Las excavaciones en el Lote B han fallado hasta ahora en recuperar algún fragmento Wari o incluso Nievería como para sugerir que la elección de las prácticas funerarias sería resultado de esta influencia pan regional.

Proponemos que la evidencia recuperada apunta a que durante la ocupación asociada a materiales Lima Tardío se da un mayor control directo y a un incremento de la presencia de la cultura Lima en el sitio de el Lote B. Esta mayor presencia se ve reflejada en el aumento de actividades de banquetes rituales y en la construcción de los edificios públicos de los sectores 3 y 4 . Es este contexto es que proponemos que el área, en el sector 4, usada como enterramiento fue suprimida con la construcción de las estructuras Lima Tardío. Siguiendo esta idea, proponemos que el entierro de niños tan cerca al conjunto habitacional de una elite local representó uno de los mecanismos por los que esta elite mantuvo una posición de prestigio sobre la dispersa población de los alrededores durante la segunda mitad del Intermedio Temprano. Quizás incluso una manera de renovar los vínculos de parentesco en los que se basaba esta posición de privilegio. De ser así, la supresión de esta área de enterramiento y la posterior construcción de una estructura secular sobre ella representó un intento de menoscabar la autoridad de estos líderes locales.

Pensamos que la evidencia de incremento de almacenamiento y festines rituales, es concomitante con un proceso de centralización política en el área. Posiblemente fruto de una estrategia para promover la adopción de la política expansiva Lima. Las excavaciones de Marcone $(2000,2010)$ en el complejo de los adobitos de Pachacamac le llevaron a proponer que la entrada de los Lima al valle de Lurín pudo estar basada en estrategias que promovían solidaridad más que diferencias sociales, a través de mecanismos de redistribución de bienes como son los festines y banquetes rituales. De ser así, estamos ante un proceso donde las bases del poder sociopolítico están cambiando de altamente rituales y abiertas, en contextos locales, a mecanismos más económicos controlados por elites regionales. Lamentablemente es difícil, por el momento, establecer si durante el periodo Lima Tardío las practicas funerarias locales fueron permitidas como durante Lima Medio o si por el contrario la presencia directa Lima implicó un abandono de estas, pues los contextos recuperados están asociados o al abandono del sitio o la pre-intrusión de Lima Tardío en el sitio

En comparación con otros entierros de niños encontrados en sitios más tempranos o contemporáneos, en el valle de Lurín y en la costa central (Ravines 1981; Sestieri 1971; Stothert y Ravines 1977; Stumer 1953; Tomasto 2005), los entierros de niños en el Lote B son notoriamente menos elaborados que el resto, en términos de la construcción de tumbas, ofrendas asociadas y manufactura de los fardos. Si bien esta simpleza en los entierros del Lote B pudiera estar relacionada con la edad de los individuos, también implica que demostraciones extravagantes de poder económico no eran necesa- 
rias o posibles para esta pequeña elite rural de poder limitado. Análisis paleopatológicos adicionales revelaron la prevalencia de escorbuto o deficiencia de vitamina C (5 de 9 individuos, 56\%) así como manifestaciones tempranas de tuberculosis (9 de 9 individuos, 100\%) (Marsteller et al., en preparación). Tentativamente esto sugiere que la población del valle de Lurín sufrió de altos grados de malnutrición e infecciones. De ser así la cooperación con los Lima pudo haber sido ventajosa, proveyendo un mayor acceso a recursos agrícolas o una mejora en términos económicos.

Aunque la mayor parte de las discusiones sobre entierros de niños en la arqueología andina han estado centradas en su carácter como contextos de sacrificio, algunos investigadores han determinado que los métodos de sacrificio y los correspondientes rituales de procesamiento del cuerpo fueron similares a los de los sacrificios de adultos (Tung y Knudson 2010). Sin embargo, creemos que antes de señalar diferencias o semejanzas económicas, sociales o religiosas entre las percepciones de los niños y los adultos en los Andes en general y en la costa central durante el periodo de transición entre el Intermedio Temprano y el Horizonte Medio en particular, se necesitan estudios adicionales. En el valle de Lurín, la excavación y estudio de grandes muestras de entierros que incluyan ambos adultos y niños son necesarias para determinar diferencias y similitudes en el patrón funerario de acuerdo a edad y así poder formular una conclusión acerca de cómo los niños del valle de Lurín y Lima en general fueron percibidos y cuáles fueron los roles sociales que cumplieron.

\section{ConcLusiones}

Para concluir, nosotros proponemos que la evidencia del Lote B parcialmente sostiene las dos hipótesis propuestas acerca de la naturaleza y momento de la expansión de la cultura Lima en el valle de Lurín, pero a ninguna de manera completa. Primero, de acuerdo con Makowski (2002), la presencia Lima en el valle de Lurín aparece en Lote B durante el Intermedio Temprano y es asociado a cerámica Lima Medio. En este periodo existían elites locales ya establecidas en el valle, aunque de limitado poder e influencia. Sin embargo, como Earle (1972) señala, existe una dramática intrusión Lima y un proceso de centralización política, que afecta a una población, reflejada en las últimas fases de ocupación del Lote B. Este proceso de centralización en el valle habría sido impuesto desde el valle del Rímac.

Este estudio demuestra que entierros "ordinarios" de niños que murieron de causas naturales pueden proveer tanto o más información sobre los procesos sociales del pasado que contextos rituales y elaborados donde los niños constituyen parte del sacrificio. Considerando las características de los entierros en el Lote B en relación con su contexto local dentro del sitio, así como con los patrones funerarios contemporáneos en la costa central, nos fue posible fortalecer nuestro entendimiento sobre la relación entre la formación política Lima y las poblaciones del valle de Lurín.

\section{Agradecimientos}

Queremos agradecer a las diversas instituciones que financiaron nuestras investigaciones en el valle de Lurín. La temporada 2009 en Lote B fue financiada por la beca Dissertation Grant Improvement \# 0837835 provista por la Academia Nacional de la Ciencia Americana (NSF) y forma parte de la investigación doctoral de Giancarlo Marcone. Fondos adicionales para estudios en Lurín le fueron provistos por la Thinker Foundation y el Centro de Estudios Latinoamericanos de la Universidad de Pittsburgh, y el Departamento de Antropología de la Universidad de Pittsburgh. Sara Marsteller fue financiada por una beca de investigación y docencia de la Escuela de evolución y Cambio Social Humano de la Universidad Estatal de Arizona. Una versión preliminar de este trabajo fue presentada en la Reunión de la Sociedad de Arqueología Americana en San Luis, Missouri 2010. 


\section{BiBLIOGRAFÍA}

BAKER, Mary

1997 "Invisibility as a symptom of gender categories in Archaeology". En: Invisible People and Processes: Writing Gender and Childhood into European Archaeology, editado por Jenny Moore y Eleanor Scott, pp. 183-191. Londres: Leicester University Press.

BAXTER, Jane Eva

2005 "Making space for children in Archaeological interpretations". Archeological Papers of the American Anthropological Association 15:77-88.

2008 The Archaeology of childhood". Annual Review of Anthropology 37:159-175.

BINFORD, Lewis R.

1971 "Mortuary practices: Their study and their potential". En: Brown JA, editor. Approaches to the Social Dimensions of Mortuary Practices. Memoirs de la Sociedad de Arqueología Americana, No. 25: 6-29.

BIRD, Douglas W. y Rebecca BLIEGE BIRD

2000 "The ethnoarchaeology of juvenile foragers: shellfishing strategies among meriam children". Journal of Anthropological Archaeology 19: 461-476.

BOURGET, Steve

2001 "Children and ancestors: ritual practices at the Moche site of Huaca de la Luna, North Coast of Peru”. En: Ritual Sacrifice in Ancient Peru, editado por Elizabeth P. Benson y Anita G. Cook, pp. 93118. Austin: University of Texas Press.

BUIKSTRA, Jane E.

1995 "Tombs for the living ... or ... for the dead: The Osmore ancestors". En: Tombs for the Living: Andean Mortuary Practices, editado por Tom D. Dillehay, pp. 229-280. Washington D.C.: Dumbarton Oaks Research Library \& Collection.

CÁRDENAS MARTIN, Mercedes

1999 Tablada de Lurín: Excavaciones 1958-1989, Patrones Funerarios, Tomo I. Pontificia Universidad Católica del Perú, Instituto Riva Agüero, Dirección Académica de Investigación, Perú.

CARR, Christopher

1995 "Mortuary practices: Their social, philosophical, religious, circumstantial and physical determinants". Journal of Archaeological Method and Theory 2: 105-200.

CCENCHO HUAMANI, José

[1999] 2001 Alfarería Pucllana propuesta de una metodología de clasificación y algunos aportes para el entendimiento de la cultura Lima. Presentado en el XII Congreso del Hombre y La Cultura Andina, Ayacucho.

CHAMBERLAIN, Andrew

2000 "Minor concerns: A demographic perspective on children in past societies". En: Children and Material Culture, editado por Joanna Sofaer Derevenski, pp. 206-212. Routledge: Florence, Kentucky, USA.

CHAPMAN, Robert, Ian HINNES y Klavs RANDSBORG (editores)

1981 The Archaeology of Death. Cambridge: Cambridge University Press.

CHARLES, Douglas K. y Jane E. BUIKSTRA

2002 "Siting, sighting and citing the dead". En: The Space and Place of Death, editado por Helaine Silverman y David B. Small, pp. 13-26. Arlington, Virgina: Archaeological Papers of the American Anthropological Association.

CHESSON, Meredith S.

2001 "Social memory, identity, and death: An introduction". Archaeological Papers of the American Anthropological Association 10: 1-10.

DeLEONARDIS, Lisa y George F. LAU

2004 "Life, death, and ancestors". En: Andean Archaeology, editado por Helaine Silverman, pp. 77-115. Oxford: Blackwell. 
DILLEHAY, Tom D.

1979 "Pre-Hispanic resource sharing in the Central Andes". Science, New Series 204: 24-31.

DUNN, Robert A.

1979 Early Intermediate period Ceramic Assemblages From Lurín Valley, Peru. Tesis de Magister inedita, Temple University.

EARLE, Timothy

1972 “Lurín Valley, Peru: early Intermediate Period settlement development”. American Antiquity 37: 467-477.

ESCOBEDO, M. y M. GOLDHAUSEN

1999 “Algunas consideraciones acerca de la iconografía Lima”. Baessler Archiv, Neue Folge XLVII: 5 -37.

FALCÓN,Víctor

2003 “El motivo Interlocking a través del ídolo de Playa Grande”. Arqueológicas (26): 163 - 178.

FINLAY, Nyree

2000 "Outside of life: Traditions of infant burial in Ireland from cillin to cist". World Archaeology 31: 407422.

FLORES, Isabel

1981 "Investigaciones arqueológicas en la Huaca Juliana, Miraflores -Lima". Boletín de Lima 13: 65-70.

2005 Pucllana: esplendor de la Cultura Lima. Lima: Instituto Nacional de Cultura.

GOLDHAUSEN, Marco

2001 “Avances en el estudio de la iconografía Lima”. Arqueológicas (25): 223-263.

GOLDSTEIN, L.

1981 "One-dimensional Archaeology and multi-dimensional People: Spatial organization and mortuary analysis". En: The Archaeology of Death, editado por Robert Chapman, Ian Kinnes, y Klavs Randsborg, pp. 53-69. Cambridge: Cambridge University Press.

GORDON, Claire C. y Jane E. BUIKSTRA

1981 "Soil pH, bone preservation, and sampling bias at mortuary sites". American Antiquity 46: 566-571.

GUERRERO, Carlos D. y Jonathan B. PALACIOS

1994 "El surgimiento del estilo Nievería en el valle del Rimac". Boletin de Lima XVI (91-96): 275-311.

HERRERA, Alexander

2007 "Social landscapes and community identity: The social organization of space in the north-central Andes". En: Socialising Complexity: Structure, Interaction and Power in Archaeological Discourse, editado por Sheila Kohring y Stephanie Wynne-Jones, pp. 161-185. Oxford: Oxbow Books.

HODDER, Ian

1982a "Sequences of structural changes in the dutch neolithic". En: Symbolic and Structural Archaeology, editado por Ian Hodder, pp. 162-177. Cambridge: Cambridge University Press.

$1982 b$ Symbols in Action. Cambridge: Cambridge University Press.

1987 "The contextual analysis of symbolic meanings". En: The Archaeology of Contextual Meanings, editado por Ian Hodder, pp. 1-10. Cambridge: Cambridge University Press.

ISLA, Elizabeth y Daniel GUERRERO

1987 "Socos: Un sitio Wari en el valle de Chillón". Gaceta arqueológica Andina 4(41): 23-28.

JIJÓN Y CAAMAÑO, Jacinto

1949 Maranga: Contribución al conocimiento de los aborígenes del Valle del Rimac, Perú. Quito: La Prensa Católica.

KAMP, Kathryn A.

2001 "Where have all the children gone?: The Archaeology of childhood". Journal of Archaeological Method and Theory 8: 1-34.

KAULICKE, Peter

2000 "La sombra de Pachacamac: Huari en la Costa Central". En: Huari y Tiwanaku: Modelos vs. Evidencias. Primera Parte, editado por Peter Kaulicke y William H. Isbell, pp. 313-358. Boletín de Arqueología PUCP No. 4. Lima: Fondo Editorial de la Pontificia Universidad Católica del Perú. 
KEITH, Kathryn

2005 "Childhood learning and the distribution of knowledge in foraging societies". Archeological Papers of the American Anthropological Association 15: 27-40.

KROEBER, Alfred

1926 The Uhle pottery collections from Supe. University of California Publications in American Archaeology and Ethnology Vol 21, $n^{\circ} 6$. Berkeley: University of California.

LAVALLÉE, Daniele

1966 “Una colección cerámica de Pachacamac". Revista del Museo Nacional 34: 220-246.

LILLEHAMMER, Grete

1989 "A child is born. The Child's World in an Archaeological perspective". Norwegian Archaeological Review 22: 89-105.

MACKAY, Martin, y Rafael SANTA CRUZ

2000 “Las excavaciones del Proyecto Arqueológico Huaca 20 (1999 y 2000)”. Boletín de Arqueología PUCP 4: 583-596.

MAKOWSKI, Krzysztof

2002 "Power and social ranking at the end of the Formative Period: The Lower Lurín Valley Cemeteries". En: Andean Archaeology 1Variations in Socio Political Organization, editado por William Isbell and Helaine Silverman, pp. 89-119. New York: Kluwer Academic/Plenum Publishers.

MARCONE F., Giancarlo

2000 "El Complejo de los Adobitos y la cultura Lima en el Santuario de Pachacamac". En: Huari y Tiwanaku: Modelos vs. Evidencias. Primera Parte, editores Peter Kaulicke y William H. Isbell. Boletín de Arqueología PUCP No. 4. Lima: Fondo Editorial de la Pontificia Universidad Católica del Perú.

2011 "What role did Wari Play in the Lima Political-Economy? The Peruvian Central Coast at the beginning of the Middle Horizon". En: Beyond Wari Walls: Regional Perpectives on Middle horizon Peru. Editor Justin Jennings. Alburquerque: University of New Mexico Press. (en prensa).

MARCUS, Joyce

1999 "Men's and women's ritual in Formative Oaxaca". En: Formative Identity and Social Organization, editado por D.C. Grove and R.A. Joyce, pp. 67-96. Washington, D.C.: Dumbarton Oaks Research Library and Collection.

MENZEL, Dorothy

1964 "Style and time in the Middle Horizon". Nawpa Pacha 2: 1-106.

MOGROVEJO, Juan y Rafael SEGURA

2000 "El Horizonte Medio en el conjunto arquitectónico Julio C. Tello de Cajamarquilla". En: Huari y Tiwanaku: Modelos vs. Evidencias, Primera parte, edited by P. Kauclicke and W. Isbell, pp. 565 -582. Boletín de Arqueología PUCP. Lima: Fondo Editorial de la Pontifica Universidad Católica del Perú.

MONTOYA, Huayta

1995 Análisis de Fragmentaría Cerámica Excavada en un Relleno de Clausura. Complejo Arqueológico "Huaca Pucllana". Tesis de licenciatura no publicada, Pontificia Universidad Católica del Perú.

NARVAEZ, Joaquin J.

2006 "Una visión General del desarrollo de las sociedades prehispánicas del valle del Rimac". Contextos 1. Estudios e investigaciones en arqueología Peruana: 111 - 164.

PARK, Robert W.

2005 "Growing up North: Exploring the Archaeology of childhood in the Thule and Dorset cultures of Arctic Canada". Archeological Papers of the American Anthropological Association 15: 53-64.

PATTERSON, Thomas C.

1966 Pattern and process in the Early Intermediate Period Pottery of the Central Coast of Peru. Publications in Anthropology 3. Berkeley: University of California.

1982 "Polities in the Lurín Valley, Peru, during the Early Intermediate Period". Nawpa Pacha 20: 61-82. 
PECHENKINA, Ekaterina A. y Mercedes DELGADO

2006 "Dimensions of health and social structure in the Early Intermediate Period cemetery at Villa El Salvador, Peru". American Journal of Physical Anthropology 131: 218-235.

PERRY, Megan A.

2005 "Redefining childhood through Bioarchaeology: Toward an archaeological and biological understanding of children in antiquity". Archeological Papers of the American Anthropological Association 15: 89-111.

RAVINES, Rogger

1977 “Practicas funerarias en Ancón (Primera parte)". Revista del Museo Nacional (Lima) 43: 327-397.

1981 “Practicas funerarias en Ancón (Segunda parte)". Revista del Museo Nacional (Lima) 45: 89-166.

REINHARD, Johan

1992 "Sacred peaks of the Andes". National Geographic 191: 36-43.

SAXE, Arthur A.

1970 Social dimensions of mortuary practices [disertación doctoral]. Ann Arbor: University of Michigan.

SCHOBINGER, Juan

1991 "Sacrifices of the high Andes". Natural History 100: 63-69.

SEGURA, Rafael

2001 Rito y economía en Cajamarquilla. Investigaciones arqueológicas en el conjunto arquitectónico Julio C. Tello. Lima: Pontificia Universidad Católica del Perú.

2004 "La cerámica Lima en los albores del Horizonte Medio y algunas notas para el debate". En: Puruchuco y la sociedad de Lima: Un homenaje a Arturo Jimenez Borja, editado por L. F. Villacorta, L. Vetter and C. Ausejo, pp. 97 -118. Lima: CONCYTEC.

SESTIERI, P. Claudio

1971 "Cajamarquilla, Peru: the necropolis on the Huaca Tello". Archaeology 24(2): 101-106.

SHADY, Ruth

1982 "Cultura Nieveria y la interacción social en el mundo andino en la época Huari". Arqueológicas 19: 5-18.

1988 “La época Huari como interacción de las sociedades regionales”. Revista Andina 6(1): 67-99.

SHADY, Ruth y José Joaquin NARVAEZ

2000 Historia prehispánica de Lima: Arqueología de la Huaca San Marcos. Lima: Museo de Arqueología y Antropología de la Universidad Nacional Mayor de San Marcos.

SHANKS Michael y Christopher TILLEY

1982 "Ideology, Symbolic power and ritual communication: A reinterpretation of Neolithic mortuary practices". En: Symbolic and Structural Archaeology, editado por Ian Hodder, pp. 129-154. Cambridge: Cambridge University Press.

SOFAER DEREVENSKI, Joanna

1994 "Where are the children? Accessing children in the Past". Archaeological Review from Cambridge 13: 7-20.

STOODLEY, Nick

2000 "From the cradle to the grave: Age organization and the early Anglo-Saxon burial rite". World Archaeology 31: 456-472.

STOTHERT, Karen E. y Rogger RAVINES

1977 "Investigaciones arqueologicas en Villa El Salvador". Revista del Museo Nacional (Lima) 43: 157-225.

STRONG, William D, y John M. CORBETT

1943 "A Ceramic sequence at Pachacamac". En: Archaeological Studies in Peru, editado por William. D. Strong, Gordon R. Willey and John M. Corbett. Columbian Studies In Archaeology and Ethnology. vol. 1 (3), New York.

STUMER, Louis M.

1953 "Playa Grande: primitive elegance in Pre-Tiahuanaco Peru". Archaeology 6(1): 42-48.

1954a "Populations centers of the Rimac Valley Peru". American Antiquity 20: 130-148. 
$1954 b$ “The Chillón Valley of Peru: excavation and reconnaissance, 1952-1953. Part 2". Archaeology 7(4): 220-228.

TOMASTO, Elsa

2005 "Tratamiento funerario de los niños en el cementerio prehispánico de Tablada de Lurín (costa central-Perú)". En: Arqueología, geografía e historia: aportes peruanos en el 50o. Congreso de Americanistas, Varsovia-Polonia, 2000, editado por Pamela Castro de la Mata Guerra, pp. 97-130. Lima: PUCPPROMPERU.

TUNG, Tiffiny A. y Kelly J. KNUDSON

2010 "Childhood lost: Abductions, sacrficie, and trophy heads of children in the Wari Empire of the ancient Andes". Latin American Antiquity 21: 44-66.

VARIOS AUTORES

1953 "Actas de la Mesa Redonda sobre Terminología Arqueológica". Boletín de la Sociedad para la Antropología Peruana, Lima.

WALKER, Phillip L., John R. JOHNSON y Patricia M. LAMBERT

1988 "Age and Sex biases in the preservation of human skeletal remains". American Journal of Physical Anthropology 76: 183-188.

WILLEY, Gordon R.

1943 "Excavations in the Chancay Valley". En: Archaeological Studies in Peru, editores William. D. Strong, Gordon R. Willey y John M. Corbett. Columbian Studies In Archaeology and Ethnology. vol. 1 (3), New York. 